\title{
QTL Mapping and Genetic Analysis of Fiber Quality Traits in Hybrid Cotton 'Ji1518'
}

Zhang Sujun *, Zhou Xiaodong *, Tang Liyuan, Li Xinghe, Wang Haitao, Liu Cunjing, Cai Xiao, Zhang Xiangyun, Zhang Jianhong Key Laboratory of Cotton Biology and Genetics and Breeding in Huanghuai-Hai Semi-arid Region, Ministry of Agriculture /National Cotton Improvement Center Hebei Branch, Ministry of Agriculture and Rural Affairs, Institute of Cotton, Hebei Academy of Agriculture and Forestry Sciences, Shijiazhuang, 050051, China

*These authors contributed equally to this work

$\square$ Corresponding author Email: mhszih@126.com

Molecular Plant Breeding, 2020, Vol.11, No.15 doi: $10.5376 / \mathrm{mpb} .2020 .11 .0015$

Received: 14 Jul., 2020

Accepted: 19 Jul., 2020

Published: 07 Aug., 2020

Copyright $\odot 2020$ Zhang et al., This article was first published in Molecular Plant Breeding in Chinese, and here was authorized to translate and publish the paper in English under the terms of Creative Commons Attribution License, which permits unrestricted use, distribution, and reproduction in any medium, provided the original work is properly cited.

Preferred citation for this article:

Zhang S.J., Zhou X.D., Tang L.Y., Li X.H., Wang H.T., Liu C.J., Cai X., Zhang X.Y., and Zhang J.H., 2020, QTL mapping and genetic analysis of fiber quality traits in hybrid cotton 'Ji1518', Molecular Plant Breeding, 11(15): 1-11 (doi: $\underline{\text { 10.5376/mpb.2020.11.0015) }}$

\begin{abstract}
Ji} 1518$ ' is a new hybrid cotton variety suitable for mechanized harvesting, the two parents of 'Ji228' and 'Ji567' were crossed to established $F_{2}, F_{2: 3}$ and $F_{2: 9}$ (recombinant inbred lines RILs) population. Simple sequence repeats (SSR) was performed to construct two different genetic maps based on the $F_{2}$ and $F_{2: 9}$ populations respectively. The QTL mapping of five fiber quality traits was performed in three populations above. A genetic map was constructed by $F_{2}$ population, which contained 15 loci in 4 linkage groups, with a full-length coverage of $237.10 \mathrm{cM}$. While the other linkage map was constructed by $\mathrm{F}_{2: 9}$ populations, which contained 45 loci in 11 linkage groups, with a full-length coverage of 554.42. Based on the inclusive composite interval mapping method with QTL IciMapping 4.1, 15 QTLs related to upper half mean length, fiber strength, the micronaire value, the elongation, and the uniformity were both detected in $\mathrm{F}_{2}$ and $\mathrm{F}_{2: 3}$ segregating populations, among them, the QTL locus $q F M-4-2$ related to the micronaire value explained the highest phenotypic variation rate at $21.10 \%$. QTLs with dominant or super-dominant effects accounted for $66.7 \%$ of the total, which showed that dominant genes were the main source of fiber quality heterosis in 'Ji1518'. Meanwhile, 6 QTLs related to the above five traits of fiber quality were detected in the RIL ( $\left.\mathrm{F}_{2: 9}\right)$ population, and the contribution rate was between $5.10 \%$ and $10.26 \%$. QTL loci related with FS and MIC were detected near HAU2349 in all three populations, and QTL loci related with FU were detected near HAU2710 in all three populations, and the markers above were linked on A6 chromosome. These stable and common QTLs are beneficial to the MAS breeding, which could improve the breeding efficiency.
\end{abstract}

Keywords Ji1518; SSR; Fiber quality; QTL mapping

Upland cotton (G. hirsutum L.) is the most important natural fiber crop in the world (Fang et al., 2017a). The fiber quality of Chinese cotton is the middle level in the world, and the high-end raw cotton still relies on imports. The fiber quality cannot meet the needs of the rapid development of Chinese textile industry (Tan, 2018). Therefore, it is necessary to carry out in-depth research on cotton fiber quality.

Cotton fiber quality is a complex quantitative trait controlled by multiple genes (Fang et al., 2017b). Due to the narrow genetic background of current upland cotton varieties and the negative genetic correlation between yield and fiber quality (Zhang et al., 2011; Clement et al., 2012; Gapare et al., 2017), the traditional breeding method is inefficient and time-consuming. If the stable major quantitative trait locus (QTL) of fiber quality were applied to practice, the breeding years would be effectively shortened.

Simple sequence repeat (SSR) markers are widely used in phenotypic trait mapping and related gene identifying. In recent ten years, breeders have used different parental segregation populations to locate cotton fiber QTLs (Zhang et al., 2005; Shen et al., 2007; Wang et al., 2007; Lacape et al., 2010; Said et al., 2013; Tang et al., 2015; Yang et al., 2015; Zhang et al., 2015). According to the statistical results of Cotton QTLdb database (Said et al., 2013; Said et al., 2015a; Said et al., 2015b), 1607 QTLs related to 5 fiber quality indexes (fiber length, fiber strength, fiber micronaire value, fiber uniformity, fiber elongation) have been preliminarily identified. However, 
due to the significant environmental impact on cotton fiber quality, the corresponding genotypes could not be determined by phenotypic values, which increased the difficulty of mapping of QTLs for fiber quality and identification of candidate genes. So far, the fine mapping of cotton fiber quality QTLs is still relatively slow. Here are some fine mappings QTLs for fiber quality using linkage mapping in recent years.

Cao et al. (2015) fine mapped the fiber length QTL ( $q F L-c h r .7)$ and fiber strength QTL ( $q F S$-chr. 7) to $0.36 \mathrm{cM}$ on chromosome 7, and the fiber micronaire value QTL ( $q F M$-chr. 7) to $0.44 \mathrm{cM}$. Liu et al. (2016) used $\mathrm{F}_{2}$ secondary segregation population (Yumian1 $\times$ RIL118) to fine map the QTL for fiber density, fiber strength, fiber micronaire value and fiber uniformity on chromosome 6 within the $0.28 \mathrm{cM}$ interval. Fang et al. (2017b) mapped the QTL for fiber strength of chromosome 7 in a $62.6 \mathrm{~kb}$ region using a $F_{2}$ population consisting of 2484 individuals and a $F_{2: 3}$ population with 2571 individuals. The interval included four genes. LRR RLK was identified as the most likely candidate gene by gene expression and comparative cloning. Xu et al. (2017) fine mapped the fiber length QTL ( $q F L-c h r 1$ ) on chromosome 1 of sea-island cotton (Gossypium barbadense) within the $0.9 \mathrm{cM}$ interval using near isogenic introgression line (NIIL) populations $\left(\mathrm{BC}_{4} \mathrm{~F}_{2}\right.$ and $\left.\mathrm{BC}_{4} \mathrm{~F}_{3}\right)$, and identified two gene expression levels were significantly positively correlated with fiber length, which may be candidate genes for fiber length QTL. Chen et al. (2018) constructed two secondary recombinant inbred lines (RILs), in which 20 and 27 QTLs related to fiber quality were detected, and further QTL clusters related to fiber length and strength were obtained on chromosome 7. Li et al. (2019) identified 103 QTLs related to fiber quality using sea-land chromosome segment introgression lines, most were distributed on subgroup $\mathrm{D}$, and focused on six chromosome segments related to fiber quality (Seg-A02-1, Seg-A06-1, Seg-A07-2, Seg-A07-3, Seg-D07-3, Seg-D06-2), proposed that more attention should be paid to the above-mentioned QTLs in fine QTL mapping. Ijaz et al. (2019) proposed that QTL mapping combined with multi-omics approaches such as, RNA sequencing datasets to identify differentially expressed genes have benefited the improvement of fiber quality, which helps to accelerate validate candidate genes and to use marker assisted selection (MAS) on fiber quality in breeding programs. Shi et al. (2020) used two land-sea backcross lines (CCRI36, CCRI45) to test the stability of three QTLs (length, strength, micronaire value) under multiple environments. 39 and 79 stably expressed QTLs were found at least two environments in the CCRI36 and CCRI45, respectively.

Previous studies have used molecular markers to locate QTLs for fiber quality traits in upland cotton, finding marker sites and genes, which laid a foundation for further study on the genetic mechanism of cotton fiber quality traits. However, there are still few major QTLs with multi environment stability (Tan, 2018). The number of molecular markers that can be used in breeding practice is obviously insufficient, so it is still necessary to identify more new major stably expressed QTLs for fiber quality in different environments for gene mapping and assisted breeding.

In order to explore the source of heterosis of fiber quality traits, and to obtain molecular markers closely linked to fiber quality, so as to provide guidance for the breeding of new hybrid cotton varieties. 'Ji1518', which was cultivated by Institute of Cotton, Hebei Academy of Agriculture and Forestry Sciences, and its two parents ('Ji228' and 'Ji567') were used to establish $\mathrm{F}_{2}, \mathrm{~F}_{2: 3}$ and $\mathrm{F}_{2: 9}$ population to carry out QTL mapping and genetic analysis of fiber quality traits in this study.

\section{Results and Analysis}

\subsection{Variation analysis of Fiber quality traits}

Analyzed the fiber quality traits of $\mathrm{P}_{1}, \mathrm{P}_{2}, \mathrm{~F}_{1}, \mathrm{~F}_{2}, \mathrm{~F}_{2: 3}$ and RIL ( $\left.\mathrm{F}_{2: 9}\right)$ populations, we found that the fiber upper half mean length and strength of the two parents were significantly different. The average of the five fiber quality indexes of ' $J 11518$ ' $\left(\mathrm{F}_{1}\right)$ were between the parents, showed a mid-parent heterosis. The fiber strength of 'Ji1518' was significantly higher than that of the two parents' average. The absolute values of skewness and kurtosis coefficient of five fiber quality indexes in $\mathrm{F}_{2}, \mathrm{~F}_{2: 3}$ and RIL $\left(\mathrm{F}_{2: 9}\right)$ populations were less than or slightly greater than 1 , which was consistent with the genetic characteristics of quantitative traits controlled by multigenic. Over parent 
lines appeared in $F_{2}, F_{2: 3}$ and $\operatorname{RIL}\left(F_{2: 9}\right)$ populations (Table 1), and some families showed the same fiber quality during purification, which indicted that there may be stably expressed QTLs expression in these families.

Table 1 Fiber quality traits of parents and generations

\begin{tabular}{|c|c|c|c|c|c|c|c|c|}
\hline Trait & $\begin{array}{l}\text { Parents/ } \\
\text { Generations }\end{array}$ & Min & Max & Average & $\begin{array}{l}\text { Coefficient of } \\
\text { variation }(\%)\end{array}$ & $\begin{array}{l}\text { Standard } \\
\text { deviation }\end{array}$ & Skewness & Kurtosis \\
\hline \multirow{6}{*}{$\begin{array}{l}\text { Fiber upper half mean length } \\
(\mathrm{mm})\end{array}$} & $\mathrm{P}_{1}$ & & & 31.24 & & 0.13 & & \\
\hline & $\mathrm{P}_{2}$ & & & 28.20 & & 0.10 & & \\
\hline & $\mathrm{F}_{1}$ & & & 30.80 & & 0.12 & & \\
\hline & $\mathrm{F}_{2}$ & 26.63 & 32.76 & 29.81 & 4.90 & 1.46 & -0.27 & -0.22 \\
\hline & $\mathrm{F}_{2: 3}$ & 28.01 & 33.23 & 30.69 & 3.26 & 1 & -0.04 & -0.36 \\
\hline & $\mathrm{F}_{2: 9}$ & 27.56 & 33.32 & 29.61 & 3.51 & 1.04 & 1.03 & 0.38 \\
\hline \multirow[t]{6}{*}{ Fiber strength $\left(\mathrm{cN} \cdot\right.$ tex $\left.^{-1}\right)$} & $\mathrm{P}_{1}$ & & & 33.50 & & 0.13 & & \\
\hline & $\mathrm{P}_{2}$ & & & 28.90 & & 0.11 & & \\
\hline & $\mathrm{F}_{1}$ & & & 33.08 & & 0.12 & & \\
\hline & $\mathrm{F}_{2}$ & 24.8 & 33.7 & 29.36 & 6.27 & 1.84 & -0.18 & -0.5 \\
\hline & $\mathrm{F}_{2: 3}$ & 28.5 & 37.5 & 32.09 & 4.92 & 1.58 & 0.15 & -0.06 \\
\hline & $\mathrm{F}_{2: 9}$ & 24.7 & 36.8 & 31.21 & 6.18 & 1.93 & -0.05 & 0.1 \\
\hline \multirow[t]{6}{*}{ Fiber micronaire value } & $\mathrm{P}_{1}$ & & & 4.43 & & 0.01 & & \\
\hline & $\mathrm{P}_{2}$ & & & 4.94 & & 0.04 & & \\
\hline & $\mathrm{F}_{1}$ & & & 4.68 & & 0.01 & & \\
\hline & $\mathrm{F}_{2}$ & 3.6 & 6.04 & 5.05 & 8.12 & 0.01 & -0.81 & 0.99 \\
\hline & $\mathrm{F}_{2: 3}$ & 3.48 & 5.71 & 4.78 & 7.74 & 0.37 & -0.23 & 0.37 \\
\hline & $\mathrm{F}_{2: 9}$ & 4.42 & 6.17 & 5.46 & 5.49 & 0.30 & -0.39 & 0.02 \\
\hline \multirow[t]{6}{*}{ Fiber elongation (\%) } & $\mathrm{P}_{1}$ & & & 6.18 & & 0.01 & & \\
\hline & $\mathrm{P}_{2}$ & & & 6.90 & & 0.06 & & \\
\hline & $\mathrm{F}_{1}$ & & & 6.63 & & 0.02 & & \\
\hline & $\mathrm{F}_{2}$ & 5.7 & 7.1 & 6.32 & 3.96 & 0.25 & 0.40 & 0.05 \\
\hline & $\mathrm{F}_{2: 3}$ & 5.7 & 6.7 & 6.23 & 2.73 & 0.17 & -0.02 & 0.21 \\
\hline & $\mathrm{F}_{2: 9}$ & 5.4 & 8.6 & 6.83 & 7.76 & 0.53 & 0.15 & -0.09 \\
\hline \multirow[t]{6}{*}{ Fiber uniformity $(\%)$} & $P_{1}$ & & & 85.03 & & 0.20 & & \\
\hline & $\mathrm{P}_{2}$ & & & 82.76 & & 0.11 & & \\
\hline & $\mathrm{F}_{1}$ & & & 83.02 & & 0.13 & & \\
\hline & $\mathrm{F}_{2}$ & 81.7 & 87.5 & 85.48 & 1.10 & 0.94 & -0.57 & 0.81 \\
\hline & $\mathrm{F}_{2: 3}$ & 80.6 & 88.5 & 84.72 & 1.51 & 1.28 & -0.28 & 0.23 \\
\hline & $\mathrm{F}_{2: 9}$ & 80.7 & 87.1 & 84.49 & 1.25 & 1.06 & -0.21 & 0.13 \\
\hline
\end{tabular}

\subsection{Correlation coefficients among fiber quality traits}

Analyzed the correlation coefficients among fiber quality traits of $\mathrm{F}_{2}, \mathrm{~F}_{2: 3}$ and RIL ( $\left.\mathrm{F}_{2: 9}\right)$ populations (Table 2), the results showed that the fiber upper half mean length is significantly correlated at $p<0.01$ with the fiber strength in each generation. The correlation coefficient was the highest in $F_{2}$ generation, which was 0.719 , and the lowest in $\mathrm{F}_{2: 9}$, was 0.209 . It was negative correlated significantly with micronaire value and elongation, and positive correlated significantly with uniformity in two generations. Fiber strength was positive correlated significantly and negative correlated significantly with uniformity and elongation, respectively, in two generations. And it was negative correlated significantly with micronaire value in generation. Micronaire value was positive correlated significantly with uniformity in two generations. And it was negative correlated significantly with elongation in generation. 
The correlation analysis of the same fiber quality index in different populations (Table 3) showed that the fiber upper half mean length, strength and micronaire value were significantly correlated $(p<0.01)$ among $\mathrm{F}_{2}, \mathrm{~F}_{2: 3}$ and $\mathrm{F}_{2: 9}$ populations. Elongation was significantly correlated $(p<0.01)$ among $\mathrm{F}_{2}$ and $\mathrm{F}_{2: 3}$, correlations coefficient was 0.201 , and was not significantly among $F_{2: 9}$, and $F_{2}, F_{2: 3}$. Uniformity was not significantly correlated among different populations.

Table 2 Correlations coefficients among fiber traits in the same generation

\begin{tabular}{llllll}
\hline Trait & Populations & Fiber upper half mean length & Fiber strength & Fiber uniformity & Fiber elongation \\
\hline Fiber strength & $\mathrm{F}_{2}$ & $0.719^{* *}$ & & \\
& $\mathrm{~F}_{2: 3}$ & $0.558^{* *}$ & & \\
& $\mathrm{~F}_{2: 9}$ & $0.209^{* *}$ & & \\
Fiber uniformity & $\mathrm{F}_{2}$ & $0.310^{* *}$ & $0.446^{* *}$ & \\
& $\mathrm{~F}_{2: 3}$ & 0.103 & -0.024 & \\
& $\mathrm{~F}_{2: 9}$ & $0.296^{* *}$ & $0.281^{* *}$ & \\
Fiber elongation & $\mathrm{F}_{2}$ & $-0.800^{* *}$ & $-0.806^{* *}$ & $-0.437^{* *}$ \\
& $\mathrm{~F}_{2: 3}$ & $-0.563^{* *}$ & $-0.468^{* *}$ & -0.118 & \\
& $\mathrm{~F}_{2: 9}$ & 0.045 & -0.112 & $0.142^{*}$ & $-0.262^{* *}$ \\
Fiber micronaire value & $\mathrm{F}_{2}$ & 0.091 & 0.113 & $0.367^{* *}$ & -0.008 \\
& $\mathrm{~F}_{2: 3}$ & $-0.289^{* *}$ & $-0.637^{* *}$ & $0.283^{* *}$ & -0.119 \\
\hline
\end{tabular}

Note: **: Significantly correlated at $p<0.01 ; *$ : Significantly correlated at $0.01<p<0.05$

Table 3 Correlation analysis of the same fiber quality traits in different generations

\begin{tabular}{llllll}
\hline & Fiber upper half mean length & Fiber strength & Micronaire value & Fiber elongation & Fiber uniformity \\
\hline $\mathrm{F}_{2} / \mathrm{F}_{2: 3}$ & $0.401^{* *}$ & $0.373^{* *}$ & $0.310^{* *}$ & $0.201^{* *}$ & 0.095 \\
$\mathrm{~F}_{2: 3} / \mathrm{F}_{2: 9}$ & $0.367^{* *}$ & $0.265^{* *}$ & $0.505^{* *}$ & -0.125 & -0.019 \\
$\mathrm{~F}_{2} / \mathrm{F}_{2: 9}$ & $0.253^{* *}$ & $0.181^{* *}$ & $0.350^{* *}$ & -0.093 & -0.005 \\
\hline
\end{tabular}

Note: **: Significantly correlated at $p<0.01$

\subsection{Construction of linkage map}

$F_{2: 9}$ population parents and $F_{1}$ were used to select 3989 pairs of SSR primers, and obtained 33 pairs of polymorphic primers, which were used to carry out genotyping for 244 individuals in $F_{2}$ population, obtained 36 polymorphic markers. Then Joinmap 3.0 was used to construct genetic maps (Figure 1A). There were 15 loci in 4 linkage groups, with a full-length coverage of $237.10 \mathrm{cM}$. The longest linkage group was $112.40 \mathrm{cM}$, the shortest was $1.30 \mathrm{cM}$, and the average of each linkage group was $59.28 \mathrm{cM}$. Each linkage group contained 2 7 markers, with an average of 3.75 markers. The average genetic distance between markers was $15.8 \mathrm{cM}$.

In order to increase the marker density of linkage map, we continued to use the DNA of parents and $\mathrm{F}_{1}$ to screen polymorphic markers. A total of 4912 SSR primers and 58 polymorphic primers were screened, accounting for $1.18 \%$ of the total primers. The genotypes of $244 \mathrm{~F}_{2: 9}$ families were detected by differential primers, and 55 polymorphic markers were obtained. The linkage relationship of molecular markers was determined by QTL IciMapping 4.1 (Figure 1B). There were 45 loci in 11 linkage groups, with a full-length coverage of $554.42 \mathrm{cM}$. The longest linkage group was $89.24 \mathrm{cM}$, the shortest was $21.82 \mathrm{cM}$, and the average of each linkage group was $46.20 \mathrm{cM}$. Each linkage group contained 2 10 markers, with an average of 4.09 markers. The average genetic distance between markers was $12.60 \mathrm{cM}$. 


\subsection{Chromosome mapping of linkage groups}

According to the information of CottonGen database (www.cottongen.org) (Yu et al., 2014a) and previous mapping results (Yu et al., 2011; Yu et al., 2014b; Chen et al., 2015), linkage groups, corresponding to A1, D10 and $\mathrm{A} 6$ chromosomes, were constructed with $\mathrm{F}_{2}$ population (Figure 1A). Linkage groups, which were constructed with RIL (F2:9), corresponding to A1, A5, A6, A7, A9/D9, A12, A13, D1, D3, D10 chromosomes, respectively (Figure 1B).

LG4

LG1/A1

LG2/D10

LG3/A6

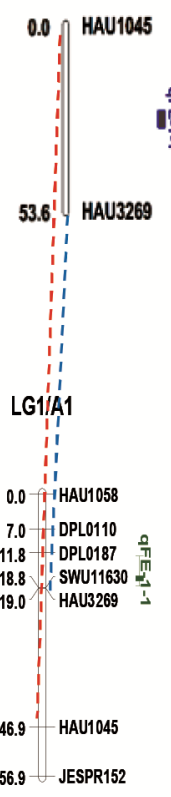
$50.0 \%$ HAU0773-1

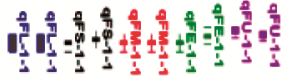
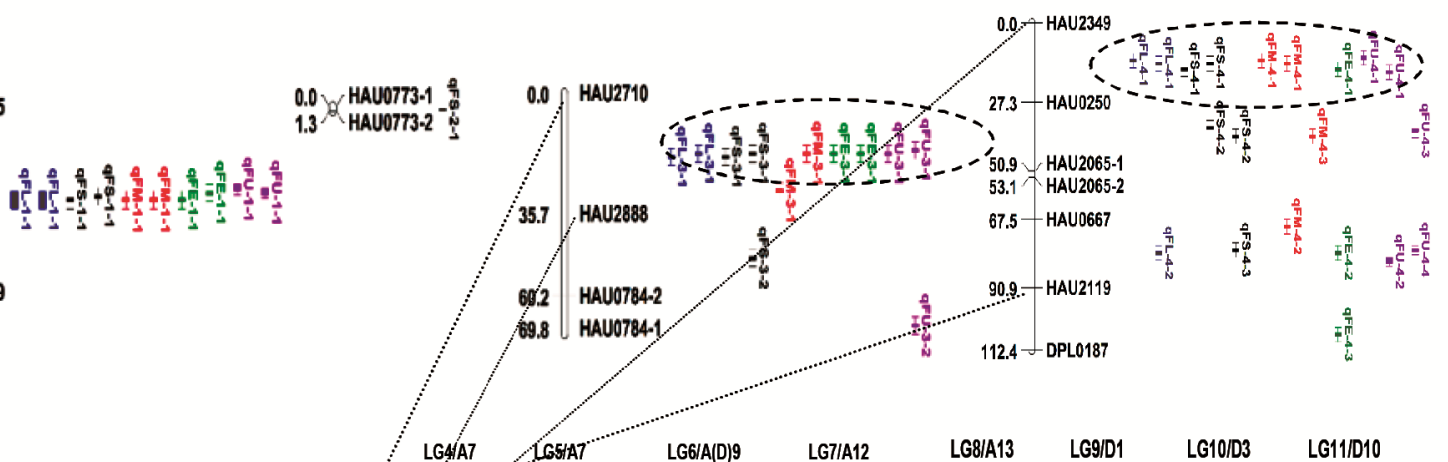

LG2/A5 LG3/A6
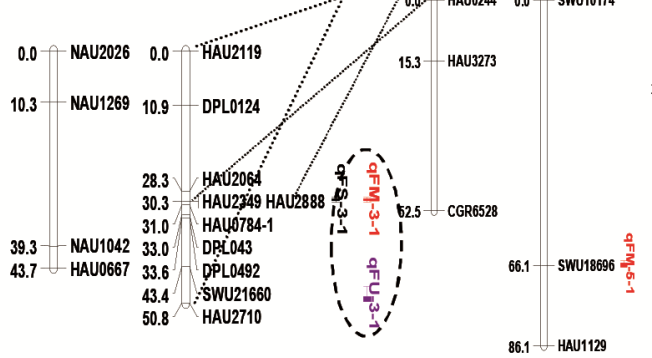

$\begin{array}{lllll}\text { LG6/A(D)9 LG7/A12 LG8/A13 LG9/D1 } & \text { LG10/D3 } & \text { LG11/D10 }\end{array}$

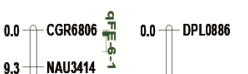

NAU344
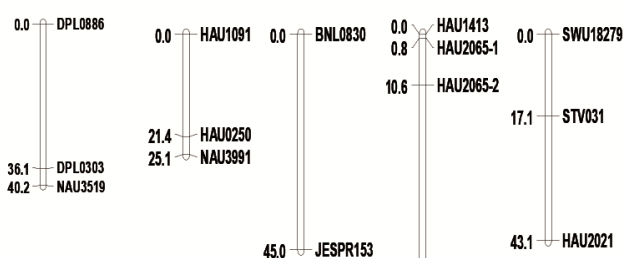

89.2 DPLO29

Fiber upper half mean length (FL)

Fiber elongation (FE)

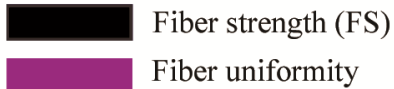

Fiber micronaire value $(\mathrm{FM})$

Figure 1 The QTL detected with fiber quality in $\mathrm{F}_{2}$ population, $\mathrm{F}_{2: 3}$ population $(\mathrm{A})$ and $\mathrm{RIL}\left(\mathrm{F}_{2: 9}\right)(\mathrm{B})$ population

\subsection{QTL mapping of fiber quality traits}

Based on the inclusive composite interval mapping method with QTL IciMapping 4.1, we analyzed the fiber quality traits in $\mathrm{F}_{2}$ and $\mathrm{F}_{2: 3}$ segregating populations. A total of 28 QTLs correlated with fiber quality traits were mapped (Figure 1; Table 4). The additive effect of QTL was $-0.62 \sim 0.29$, and the dominant effect was $-2.47 \sim 1.01$, which could explain $0.77 \% \sim 21.10 \%$ phenotypic variation. Among them, 4 QTLs were correlated with the Fiber upper half mean length, 7 were correlated with the fiber strength, and 5 were correlated with the micronaire value. 5 and 7 QTLs were correlated with elongation and uniformity, respectively. 15 QTLs could be detected in $F_{2}$ and $\mathrm{F}_{2: 3}$ populations at the same time. 
Molecular Plant Breeding 2020, Vol.11, No.15, 1-11

$\mathrm{http} / / /$ genbreedpublisher.com/index.php/mpb

Table 4 The QTL detected with fiber quality in $\mathrm{F}_{2}$ population and $\mathrm{F}_{2: 3}$ population

\begin{tabular}{|c|c|c|c|c|c|c|c|c|c|c|}
\hline Traits & $\begin{array}{l}\text { QTL } \\
\text { name }\end{array}$ & $\begin{array}{l}\text { Gene- } \\
\text { ration }\end{array}$ & $\begin{array}{l}\text { Linkage group/ } \\
\text { Chromosome }\end{array}$ & Position & $\begin{array}{l}\text { Left } \\
\text { marker }\end{array}$ & $\begin{array}{l}\text { Right } \\
\text { marker }\end{array}$ & LOD & $\begin{array}{l}\text { Additive } \\
\text { effect }\end{array}$ & $\begin{array}{l}\text { Dominant } \\
\text { effect }\end{array}$ & $\begin{array}{l}\text { Contribution } \\
\text { rate }(\%)\end{array}$ \\
\hline \multirow{7}{*}{$\begin{array}{l}\text { Fiber upper } \\
\text { half } \\
\text { mean length }\end{array}$} & \multirow[t]{2}{*}{$q F L-1-1$} & $\mathrm{~F}_{2}$ & 1/A1 & 27 & HAU1045 & HAU3269 & 5.42 & -0.20 & 0.66 & 5.35 \\
\hline & & $\mathrm{F}_{2: 3}$ & $1 / \mathrm{A} 1$ & 27 & HA7U1045 & HAU3269 & 5.16 & 0.03 & -0.23 & 2.92 \\
\hline & \multirow[t]{2}{*}{$q F L-3-1$} & $\mathrm{~F}_{2}$ & 3/A6 & 19 & HAU2710 & HAU2888 & 4.67 & -0.22 & 0.30 & 3.35 \\
\hline & & $\mathrm{F}_{2: 3}$ & 3/A6 & 18 & HAU2710 & HAU2888 & 4.39 & -0.05 & 0.42 & 2.94 \\
\hline & \multirow[t]{2}{*}{$q F L-4-1$} & $\mathrm{~F}_{2}$ & 4 & 13 & HAU2349 & HAU0250 & 2.79 & -0.16 & 0.14 & 1.66 \\
\hline & & $\mathrm{F}_{2: 3}$ & 4 & 14 & HAU2349 & HAU0250 & 2.68 & 0.08 & 0.26 & 1.61 \\
\hline & $q F L-4-2$ & $\mathrm{~F}_{2}$ & 4 & 79 & HAU0667 & HAU2119 & 2.94 & -0.20 & 0.08 & 2.19 \\
\hline \multirow[t]{11}{*}{ Fiber strength } & \multirow[t]{2}{*}{$q F S-1-1$} & $\mathrm{~F}_{2}$ & $1 / \mathrm{A} 1$ & 27 & HAU1045 & HAU3269 & 5.05 & -0.04 & 0.31 & 1.49 \\
\hline & & $\mathrm{F}_{2: 3}$ & $1 / \mathrm{A} 1$ & 26 & HAU1045 & HAU3269 & 5.42 & -0.09 & 0.65 & 2.93 \\
\hline & $q F S-2-1$ & $\mathrm{~F}_{2}$ & 2/A10 & 1 & HAU0773a & HAU0773b & 3.08 & -0.61 & 0.08 & 6.01 \\
\hline & \multirow[t]{2}{*}{$q F S-3-1$} & $\mathrm{~F}_{2}$ & 3/A6 & 49 & HAU2710 & HAU2888 & 4.04 & -0.13 & -0.31 & 1.87 \\
\hline & & $\mathrm{F}_{2: 3}$ & 3/A6 & 18 & HAU2710 & HAU2888 & 4.36 & 0.14 & 0.20 & 1.89 \\
\hline & $q F S-3-2$ & $\mathrm{~F}_{2}$ & 3/A6 & 49 & HAU2888 & HAU0784b & 2.80 & -0.24 & -0.95 & 6.36 \\
\hline & \multirow[t]{2}{*}{$q F S-4-1$} & $\mathrm{~F}_{2}$ & 4 & 16 & HAU2349 & HAU0250 & 3.45 & -0.24 & 0.74 & 4.87 \\
\hline & & $\mathrm{F}_{2: 3}$ & 4 & 14 & HAU2349 & HAU0250 & 2.88 & 0.10 & 0.64 & 3.33 \\
\hline & \multirow[t]{2}{*}{$q F S-4-2$} & $\mathrm{~F}_{2}$ & 4 & 36 & HAU0250 & HAU2065a & 3.12 & -0.19 & 0.94 & 6.21 \\
\hline & & $\mathrm{F}_{2: 3}$ & 4 & 39 & HAU0250 & HAU2065a & 4.87 & -0.41 & 0.76 & 9.76 \\
\hline & $q F S-4-3$ & $\mathrm{~F}_{2}$ & 4 & 78 & HAU0667 & HAU2119 & 6.20 & -0.62 & 1.01 & 13.14 \\
\hline \multirow{8}{*}{$\begin{array}{l}\text { Fiber } \\
\text { micronaire } \\
\text { value }\end{array}$} & \multirow[t]{2}{*}{$q F M-1-1$} & $\mathrm{~F}_{2}$ & $1 / \mathrm{A} 1$ & 27 & HAU1045 & HAU3269 & 5.59 & -0.05 & 0.24 & 5.77 \\
\hline & & $\mathrm{F}_{2: 3}$ & $1 / \mathrm{A} 1$ & 27 & HAU1045 & HAU3269 & 5.18 & -0.01 & 0.02 & 2.10 \\
\hline & \multirow[t]{2}{*}{$q F M-3-1$} & $\mathrm{~F}_{2}$ & 3/A6 & 29 & HAU2710 & HAU2888 & 6.97 & 0.04 & -0.80 & 19.69 \\
\hline & & $\mathrm{F}_{2: 3}$ & 3/A6 & 18 & HAU2710 & HAU2888 & 4.07 & 0.01 & -0.01 & 1.03 \\
\hline & \multirow[t]{2}{*}{$q F M-4-1$} & $\mathrm{~F}_{2}$ & 4 & 13 & HAU2349 & HAU0250 & 2.52 & 0.00 & -0.12 & 1.55 \\
\hline & & $\mathrm{F}_{2: 3}$ & 4 & 14 & HAU2349 & HAU0250 & 3.15 & -0.01 & -0.19 & 5.01 \\
\hline & $q F M-4-2$ & $\mathrm{~F}_{2}$ & 4 & 70 & HAU0667 & HAU2119 & 4.00 & -0.01 & -0.97 & 21.10 \\
\hline & $q F M-4-3$ & $\mathrm{~F}_{2: 3}$ & 4 & 39 & HAU0250 & HAU2065a & 5.67 & 0.12 & -0.13 & 10.65 \\
\hline \multirow{7}{*}{$\begin{array}{l}\text { Fiber } \\
\text { elongation }\end{array}$} & \multirow[t]{2}{*}{$q F E-1-1$} & $\mathrm{~F}_{2}$ & $1 / \mathrm{A} 1$ & 27 & HAU1045 & HAU3269 & 5.53 & 0.05 & -0.12 & 4.38 \\
\hline & & $\mathrm{F}_{2: 3}$ & 1/A1 & 25 & HAU1045 & HAU3269 & 5.57 & 0.01 & -0.10 & 6.67 \\
\hline & \multirow[t]{2}{*}{$q F E-3-1$} & $\mathrm{~F}_{2}$ & 3/A6 & 18 & HAU2710 & HAU2888 & 3.97 & 0.02 & 0.01 & 2.39 \\
\hline & & $\mathrm{F}_{2: 3}$ & 3/A6 & 18 & HAU2710 & HAU2888 & 4.29 & -0.01 & -0.03 & 1.01 \\
\hline & $q F E-4-1$ & $\mathrm{~F}_{2: 3}$ & 4 & 16 & HAU2349 & HAU0250 & 2.83 & -0.01 & 0.05 & 2.60 \\
\hline & $q F E-4-2$ & $\mathrm{~F}_{2: 3}$ & 4 & 79 & HAU0667 & HAU2119 & 2.89 & -0.01 & 0.09 & 4.09 \\
\hline & $q F E-4-3$ & $\mathrm{~F}_{2: 3}$ & 4 & 107 & HAU2119 & DPL0187 & 3.69 & -0.06 & 0.04 & 8.98 \\
\hline \multirow{10}{*}{$\begin{array}{l}\text { Fiber } \\
\text { uniformity }\end{array}$} & \multirow[t]{2}{*}{$q F U-1-1$} & $\mathrm{~F}_{2}$ & $1 / \mathrm{A} 1$ & 25 & HAU1045 & HAU3269 & 5.38 & -0.21 & -0.55 & 6.61 \\
\hline & & $\mathrm{F}_{2: 3}$ & 1/A1 & 26 & HAU1045 & HAU3269 & 5.22 & 0.08 & -0.16 & 0.77 \\
\hline & \multirow[t]{2}{*}{$q F U-3-1$} & $\mathrm{~F}_{2}$ & 3/A6 & 18 & HAU2710 & HAU2888 & 4.40 & 0.02 & -0.89 & 8.13 \\
\hline & & $\mathrm{F}_{2: 3}$ & 3/A6 & 17 & HAU2710 & HAU2888 & 4.89 & -0.12 & 0.40 & 3.80 \\
\hline & $q F U-3-2$ & $\mathrm{~F}_{2}$ & 3/A6 & 69 & HAU0784b & HAU0784a & 2.56 & -0.15 & -2.47 & 14.74 \\
\hline & \multirow[t]{2}{*}{$q F U-4-1$} & $\mathrm{~F}_{2}$ & 4 & 12 & HAU2349 & HAU0250 & 3.02 & -0.23 & -0.16 & 2.51 \\
\hline & & $\mathrm{F}_{2: 3}$ & 4 & 17 & HAU2349 & HAU0250 & 3.20 & 0.22 & 0.25 & 4.40 \\
\hline & $q F U-4-2$ & $\mathrm{~F}_{2}$ & 4 & 83 & HAU0667 & HAU2119 & 3.92 & -0.29 & -1.55 & 23.96 \\
\hline & $q F U-4-3$ & $\mathrm{~F}_{2: 3}$ & 4 & 37 & HAU0250 & HAU2065a & 3.88 & 0.29 & 0.50 & 11.33 \\
\hline & $q F U-4-4$ & $\mathrm{~F}_{2: 3}$ & 4 & 79 & HAU0667 & HAU2119 & 2.60 & 0.03 & -0.35 & 1.93 \\
\hline
\end{tabular}

The contribution rate of 4 QTLs correlated with the fiber upper half mean length was between $1.61 \%$ and $5.35 \%$. According to the $|\mathrm{D} / \mathrm{A}|$ effect, $q F L-1-1, q F L-3-1$ were super-dominant. $q F L-4-1$ showed dominant and super-dominant in $\mathrm{F}_{2}$ and $\mathrm{F}_{2: 3}$ segregation population, respectively. $q F L-4-2$ showed partial-dominant in $\mathrm{F}_{2}$ segregation population. The contribution rate of 7 QTLs correlated with the fiber strength was $1.49 \% \sim 13.14 \%$. 
$q F S$-2-1 showed additive effect in $\mathrm{F}_{2}$, and others showed super-dominant. The contribution rate of 5 QTLs correlated with the micronaire value was $2.10 \% \sim 21.10 \%$. All of them showed super-dominant or dominant. The contribution rate of 5 QTLs correlated with the elongation was $1.01 \% \sim 8.98 \%$. qFE-3-1, qFE-4-3 showed partial-dominant, and others were super-dominant. The contribution rate of 7 QTLs correlated with the uniformity was $0.77 \% \sim 23.96 \%$. All of them showed super-dominant or partial-dominant. In a word, among the QTLs controlling fiber quality, $66.7 \%$ of the QTLs were dominant or super-dominant phenotypes, $26.6 \%$ were partial-dominant and $6.7 \%$ were additive effects. Dominant gene is the main source of fiber quality heterosis in ' $\mathrm{Ji}$ 1518 .

Based on the inclusive composite interval mapping method with QTL IciMapping 4.1, we analyzed the fiber quality traits in RIL $\left(\mathrm{F}_{2: 9}\right)$ populations. A total of 6 QTLs correlated with fiber quality traits were mapped (Figure 1B; Table 5). Among them, 1 QTL was correlated with fiber strength, 2 QTLs were correlated with micronaire value, and elongation, 1 QTL was correlated with uniformity. They were located on chromosomes A1, A6, A7 and A9/D9, respectively. The genetic effect was mainly additive effect because the later generations of RIL population tend to be homozygous (Chen et al., 2015). The obtained QTL additive effect was between -0.52 and 0.17. Contribution rate was between $5.10 \%$ and $10.26 \%$. $q F S-3-1$ additive effect was -0.52 , additive gene was from female parent 'Ji228', contribution rate was $5.10 \%$. Additive effect of $q F M-3-1$ and $q F M-5-1$ were 0.07 and 0.08 , respectively. Both additive genes were from male parent ' $\mathrm{J} 5567$ '. Contribution rate were $5.29 \%$ and $7.51 \%$, respectively. $q F U-3-1$ additive effect was -0.30 . Additive gene was from female parent 'Ji228' $q F E-6-1$ additive effect was -0.24. Additive gene was from female parent 'Ji228'. Contribution rate was $7.42 \%$. $q F E-1-2$ additive effect was 0.17 . Additive gene was from male parent 'Ji567'. Contribution rate was $10.26 \%$.

Table 5 The QTL detected with fiber quality in $\operatorname{RIL}\left(\mathrm{F}_{2: 9}\right)$ population

\begin{tabular}{|c|c|c|c|c|c|c|c|c|c|}
\hline Traits & QTL name & Generation & $\begin{array}{l}\text { Linkage } \\
\text { group/ } \\
\text { Chromosome }\end{array}$ & Position & $\begin{array}{l}\text { Left } \\
\text { marker }\end{array}$ & $\begin{array}{l}\text { Right } \\
\text { marker }\end{array}$ & LOD & $\begin{array}{l}\text { Additive } \\
\text { effect }\end{array}$ & $\begin{array}{l}\text { Contribution } \\
\text { rate }(\%)\end{array}$ \\
\hline $\begin{array}{l}\text { Fiber } \\
\text { strength }\end{array}$ & $q F S-3-1$ & $\operatorname{RIL}\left(\mathrm{F}_{2: 3}\right)$ & 3/A6 & 30 & HAU2064 & HAU2349 & 2.75 & -0.52 & 5.10 \\
\hline Fiber & $q F M-3-1$ & $\operatorname{RIL}\left(\mathrm{F}_{2: 3}\right)$ & 3/A6 & 30 & HAU2064 & HAU2349 & 2.54 & 0.07 & 5.29 \\
\hline $\begin{array}{l}\text { micronaire } \\
\text { value }\end{array}$ & $q F M-5-1$ & $\operatorname{RIL}\left(\mathrm{F}_{2: 3}\right)$ & 5/A7 & 66 & SWU10174 & SWU18696 & 4.55 & 0.08 & 7.51 \\
\hline $\begin{array}{l}\text { Fiber } \\
\text { uniformity }\end{array}$ & $q F U-3-1$ & $\operatorname{RIL}\left(\mathrm{F}_{2: 3}\right)$ & 3/A6 & 50 & SWU21660 & HAU2710 & 3.33 & -0.30 & 6.38 \\
\hline Fiber & $q F E-6-1$ & $\operatorname{RIL}\left(F_{2: 9}\right)$ & 6/A(D)9 & 1 & CGR6806 & NAU3414 & 3.86 & -0.24 & 7.42 \\
\hline elongation & $q F E-1-1$ & $\operatorname{RIL}\left(\mathrm{F}_{2: 9}\right)$ & $1 / \mathrm{A} 1$ & 17 & DPL0187 & SWU11630 & 5.65 & 0.17 & 10.26 \\
\hline
\end{tabular}

\section{Discussion}

\subsection{Multi generation consistency analysis of QTLs for fiber quality traits}

Cotton fiber quality has complex genetic background and is susceptible to environmental influence (Zhang, 2015). Stably expressed QTL existed in multiple generations indicated that genetic background more strongly impacts on fiber quality traits. And it was valuable to be used in molecular marker assisted breeding (Lacape et al., 2009). Comparing the mapping results between the primary segregation population and the secondary population, QTLs related to the five fiber quality indexes could be repeatedly detected in the section between HAU2710 and HAU2888, HAU2349 and HAU0250, HAU0667 and HAU2119, which are marked by SSR in $\mathrm{F}_{2}$ and $\mathrm{F}_{2: 3}$. After using $\mathrm{F}_{2: 9}$ to reconstruct the map, the above segments were located in the same linkage group on chromosome A6. In this segment, loci related to fiber quality ( $\mathrm{F}_{2}$ or $\mathrm{F}_{2: 3}: q F L-4-1, q F S-4-1, q F M-4-1, q F U-4-1, q F L-3-1, q F S-3-1$, $\left.q F M-3-1, q F E-4-1, q F U-3-1 ; \mathrm{F}_{2: 9}: q F S-3-1, q F M-3-1, q F U-3-1\right)$ were detected near HAU2349 and HAU2710 in $\mathrm{F}_{2}, \mathrm{~F}_{2: 3}$ and secondary RIL $\left(\mathrm{F}_{2: 9}\right)$ populations. These loci are highly stable independent of generations and may be valuable for marker assisted selection. 
Besides, QTLs related to five fiber quality indexes were detected in HAU1045 and HAU3269 segments of A1 chromosome in $\mathrm{F}_{2}$ and $\mathrm{F}_{2: 3}$ segregation populations. After adding markers, QTLs related to elongation ( $\left.q F E-1-1\right)$ were detected on A1 chromosome near HAU1045-HAU3269 segment with the help of $\mathrm{F}_{2: 9}$ population.

On the whole, the QTLs for fiber quality in $\mathrm{F}_{2}$ and $\mathrm{F}_{2: 3}$ populations of lower generation had better repeatability, and multiple QTLs related to fiber quality traits showed cluster distribution. This also exists in other studies with primary group mapping (Liu et al., 2016; Qiao et al., 2019). This phenomenon may be more obvious due to the low density of genetic map constructed by the primary population in this study. In the secondary mapping population, QTL loci related to a fiber quality index could be located near the QTL cluster related to fiber quality. The results showed that stably expressed QTL existed in the QTL cluster, which is greatly affected by genotype. Meanwhile, compared with the mapping results of the primary population, the number of loci mapped by the secondary RIL population decreased, which may be due to the weakening or disappearance of some non-major loci in the process of multi generation breeding.

\subsection{Consistency analysis of reported loci}

Liu et al. (2016) used $6975 \mathrm{~F}_{2}$ to map QTLs correlated with fiber length, strength, micronaire value, and uniformity at the same time on chromosome A6 of upland cotton. SSR markers on both sides were HAU2119 and SWU2302. In this study, QTLs correlated with fiber length, strength, micronaire value and uniformity $\left(\mathrm{F}_{2}\right.$ or $\mathrm{F}_{2: 3 \text { : }}$ $q F L-4-2, q F S-4-3, q F M-4-3, q F E-4-3, q F U-4-4)$ were also located near HAU2119 in $\mathrm{F}_{2}$ or $\mathrm{F}_{2: 3}$ segregation population, inferred it was same or similar with QTLs mapped by Liu et al. (2016). And QTLs correlated with fiber quality were detected in $\mathrm{F}_{2}, \mathrm{~F}_{2: 3}$ and secondary RIL $\left(\mathrm{F}_{2: 9}\right)$ populations. While in the RIL ( $\left.\mathrm{F}_{2: 9}\right)$ populations, the distance between $q F S-3-1, q F M-3-1$ and HAU2349 was $0.31 \mathrm{cM}$, and that of between $q F U-3-1$ and HAU2710 was $0.84 \mathrm{cM}$. The above QTLs and HAU2119 were in the same linkage group, but no common markers were found in the CottonGen database (Yu et al., 2014a). It was inferred that these QTLs were new linked to Liu et al. (2016). These loci or genes related to fiber quality control have strong linkage relationship, which is worthy of further study.

In addition, after comparison, it was found that the QTL loci $q F E-4-1$ found in $\mathrm{F}_{2: 3}$ population was partially coincident with that correlated with elongation found by Tang et al. (2015). The QTL loci correlated with micronaire value and elongation were mapped on chromosomes A1, A7 and A/D9 by subpopulation. Due to the lack of common markers with previous mapping results, this QTL loci may be newly detected in this study.

In conclusion, QTL mapping for fiber quality traits was carried out in primary population and secondary population, and stable genetic loci were obtained for multiple generations in this study. Through the consistency analysis with reported loci, we not only mapped QTLs or loci consistent with previous results, but also mapped new QTL loci, which can reflect the reliability and innovation of this study.

\section{Materials and Methods}

\subsection{Experiment materials}

'Ji1518' is a hybrid cotton variety (cotton 2014005, cotton 20189001) suitable for mechanized harvesting, which was crossed by the two parents of 'Ji228' and 'Ji567'. The female parent 'Ji228' (cotton 2008003) ( $\left.\mathrm{P}_{1}\right)$ was a high-quality fiber trait, and its strength and upper half mean length were outstanding. The male parent 'Ji567' $\left(\mathrm{P}_{2}\right)$ was a high-quality fiber trait bred by Ji668 $\times$ GK12. 'Ji1518' $\mathrm{F}_{1}$ seeds were obtained by crossing two parents in Xiaoanshe, Shijiazhuang in the summer of 2008. In 2010, $\mathrm{F}_{2}$ genetic population was constructed and strictly self-crossed. In 2011, $244 \mathrm{~F}_{2: 3}$ lines were planted. After multiple generations of self-crossed, each family was relatively stable $\left(F_{2: 9}\right)$. In 2017, 244 recombinant inbred lines (RILs) were obtained. $F_{2: 3}$ and RIL ( $\left.F_{2: 9}\right)$ populations were completely randomized design, single line, length of $7.5 \mathrm{~m}$, line distance of $0.8 \mathrm{~m}$, plant distance of $18 \sim 20 \mathrm{~cm}$. And carry out routine test management.

\subsection{Fiber quality detection and data statistics}


Determined the fiber quality data of $F_{1}, F_{2}, F_{2: 3}$ and RIL $\left(F_{2: 9}\right)$ populations. In the middle of September, 30 open bolls were randomly harvested in the middle of each strain and sent to CIQ of Hebei Province for testing. Each sample was tested three times. Testing index include the fiber upper half mean length (FL), fiber strength (FS), fiber micronaire value (FM), fiber elongation (FE), and fiber uniformity (FU). Analyze-Descriptive statistics-Descritives of SPSS 19.0 was used to carry out descriptive statistical analysis of fiber quality traits.

\subsection{Construction of genetic linkage map}

Genomic DNA was extracted from young cotton leaves by improved CTAB method (Parerson et al., 1993). SSR primer sequences were obtained from CottonGen (http://www.com.cottongen.org/) database (Yu et al., 2014a) and Cotton Marker Database (http://www. cottonmarker.org/). Conventional amplification method was used to separate RCR products by $8 \%$ polyacrylamide gel electrophoresis, and silver staining was carried out with reference to Zhang et al. (2000). Refer to the method of Tang et al. (2018) for statistical marker band type. Genetic map construction: Joinmap4.0 was used to construct molecular marker linkage maps in $\mathrm{F}_{2}$ groups. The lowest LOD value of linkage was 3.0. QTL IciMapping 4.1 was used to construct molecular marker linkage maps in $\mathrm{F}_{2: 9}$ groups, LOD was selected as 3.0, the algorithm is nnTwoOpt and the standard is SARF. ICIM-ADD method of QTL IciMapping 4.1 was used to map QTLs correlated with fiber quality in $F_{2}, F_{2: 3}$, and RIL ( $\left.F_{2: 9}\right)$ populations. LOD $\geq 2.5$ was used as a threshold to screen QTLs with additive or dominant effects. According to the method of Stuber et al. (1992), the dominant potential was used to determine the gene effect type of each QTL, and the Map Chart 2.2 was used to draw the distribution map of QTL on the linkage group. QTL was named according to QTL (q) + trait name (abbreviation) + linkage group (number) + QTL number (number).

\section{Authors' contributions}

ZSJ and ZXD designed and carried out this experiment. TLY and LXH performed the statistical analysis. WHT, LCJ, CX, and ZXY participated in the design of the study and results analysis. ZJH conceived of the study, and guide its design, data analysis, draft, and revision of the manuscript. All authors read and approved the final manuscript.

\section{Acknowledgments}

This study was supported by Major State Research Development Program (2016YFD0101415), Innovation Project of Hebei Academy of Agriculture and Forestry Sciences (2019-3-7-1; 2019-3-7-4), and Open Project of State Key Laboratory of Cotton Biology (CB2018A15). Thanks to Shu Jinshai, associate researcher from Institute of Vegetables and Flowers, Chinese Academy of Agricultural Sciences.

\section{Reference}

Cao Z., Zhu X., Chen H., and Zhang T., 2015, Fine mapping of clustered quantitative trait loci for fiber quality on chromosome 7 using a Gossypium barbadense introgressed line, Mol. Breeding, 35: 215 https://doi.org/10.1007/s11032-015-0393-3

Chen H.D., Khan M.K., Zhou Z.L., Wang X.X., Cai X.Y., Kashifllyas M., Wang C.Y., WangY.H., Li Y.Q., Liu F., and Wang K.B., 2015, A high-density SSR genetic map constructed from a $\mathrm{F}_{2}$ population of Gossypium hirsutum and Gossypium darwinii, Gene, 574(2): 273-286 https://doi.org/10.1016/j.gene.2015.08.022 PMid:26275937

Chen Y., Liu G., Ma H., Song Z.Q., Zhang C.Y., Zhang J.X., Zhang J.H., Wang F.R., and Zhang J., 2018, Identification of introgressed alleles conferring high fiber quality derived from Gossypium barbadense L. in secondary mapping populations of G. hirsutum L., Front. Plant Sci., 9 : 1023 https://doi.org/10.3389/fpls.2018.01023 PMid:30073008 PMCid:PMC6058274

Clement J.D., Constable G.A., Stiller W.N., and Liu S.M., 2012, Negative associations still exist between yield and fibre quality in cotton breeding programs in Australia and USA, Field Crops Res., 128: 1-7 https://doi.org/10.1016/j.fcr.2011.12.002

Fang L., Wang Q., Hu Y., Jia Y., Chen J., Liu B., Zhang Z.Y., Guan X.Y., Chen S.Q., Zhou B.L., Mei G.F., Sun J.L., Pan Z., He S.P., Xiao S.H., Shi W.J., Gong W.F., Liu J.G., Ma J., Cai C.P., Zhu X.F., Guo W.Z., Du X.M., and Zhang T.Z., 2017a, Genomic analyses in cotton identify signatures of selection and loci associated with fiber quality and yield traits, Nat. Genet., 49(7): 1089-1098 https://doi.org/10.1038/ng.3887 PMid:28581501 
Fang X.M., Liu X.Y., Wang X.Q., Wang W.W., Liu D.X., Zhang J., Liu D.J., Teng Z.H., Tan Z.Y., Liu F., Zhang F.J., Jiang M.C., Jia X.L., Zhong J.W., Yang J.H., and Zhang Z.S., 2017b, Fine-mapping q FS07.1 controlling fiber strength in upland cotton (Gossypium hirsutum L.), Theor. Appl. Genet., 130(4): 795-806 https://doi.org/10.1007/s00122-017-2852-1 PMid:28144698

Gapare W., Conaty W., Zhu Q.H., Liu S., Stiller W., Llewellyn D., and Wilson I., 2017, Genome-wide association study of yield components and fibre quality traits in a cotton germplasm diversity panel, Euphytica, 213(3): 6666 https://doi.org/10.1007/s10681-017-1855-y

Ijaz B., Zhao N., Kong J., and Hua J.. 2019, Fiber quality improvement in upland cotton (Gossypium hirsutum L.): quantitative trait loci mapping and marker assisted selection application, Front. Plant Sci., 10: 1585

https://doi.org/10.3389/fpls.2019.01585

PMid:31921240 PMCid:PMC6917639

Lacape J.M., Jacobs J., Arioli T., Derijcker R., Forestier C.N., Llewellyn D., Jean J., Thomas E., and Viot C., 2009, A new interspecific, Gossypium hirsutum Ã-G. barbadense, RIL population: towards a unified consensus linkage map of tetraploid cotton, Theor. Appl. Genet., 119(2): 281-292 https://doi.org/10.1007/s00122-009-1037-y PMid:19387609

Lacape J.M., Llewellyn D., Jacobs J., Arioli T., Becker D., Calhoun S., Ghazi Y.A., Liu S.M., Palai O., Georges S., Giband M., Henrique A., Barroso V., Claverie M., Gawryziak g., Jean J., Vialle M., and Viot C., 2010, Meta-analysis of cotton fiber quality QTLs across diverse environments in a Gossypium hirsutum $\times$ G.barbadense RIL population, BMC Plant Biol., 10: 107-113

https://doi.org/10.1186/1471-2229-10-132 PMid:20584292 PMCid:PMC3017793

Li S.Q., Liu A.Y., Kong L.L., Gong J.W., Li J.W., Gong W.K., Lu Q.W., Li P.T., Ge Q., Shang H.H., Xiao X.H., Liu R.X., Zhang Q., Shi Y.Z., and Yuan Y.L., 2019, QTL mapping and genetic effect of chromosome segment substitution lines with excellent fiber quality from Gossypium hirsutum $\times$ Gossypium barbadense, Mol. Genet. Genomics, 294(5): 1123-1136 https://doi.org/10.1007/s00438-019-01566-8 PMid:31030276

Liu D.X., Zhang J.L., Wang X.Y., Liu W.W., Liu D.J., Teng Z.H., Fang X.M., Tan Z.Y., Tang S.Y., Yang J.H., Zhong J.W., and Zhang Z.S., 2016, Fine mapping and RNA-seq unravels candidate genes for a major QTL controlling multiple fiber quality traits at the $\mathrm{T}_{1}$ region in upland cotton, BMC Genomics, 17(1), 295

https://doi.org/10.1186/s12864-016-2605-6 PMid:27094760 PMCid:PMC4837631

Parerson A.H., Brubaker C.L., and Wendel J.F., 1993, A rapid method for extraction of cotton (Gossypium spp.) genomic DNA suitable for RFLP and PCR analysis, Plant Mol. Biol. Rep., 11(2): 122-127 https://doi.org/10.1007/BF02670470

Qiao W.Q., Yan G.T., Shi J.B., Wang N., Zhang Y.L., Xu Q.H., Zhou H., and Huang Q., 2019, QTL mapping of fiber quality in low-generation upland cotton populations and functional annotation of candidate genes, Mianhua Xuebao (Cotton Science), 31(4): 282-296

Said J.I., Knapka J.A., Song M.Z., and Zhang J.F., 2015a, Cotton QTLdb: a cotton QTL database for QTL analysis, visualization, and comparison between Gossypium hirsutum and G. hirsutum x G. barbadense populations, Mol. Genet. Genomics, 290(4): 1615-1625 https://doi.org/10.1007/s00438-015-1021-y PMid:25758743

Said J.I., Lin Z.X., Zhang X.L., Song M.Z., and Zhang J.F., 2013, A comprehensive meta QTL analysis for fiber quality, yield, yield related and morphological traits, drought tolerance, and disease resistance in tetraploid cotton, BMC Genomics, 14: 776

https://doi.org/10.1186/1471-2164-14-776 PMid:24215677 PMCid:PMC3830114

Said J.I., Song M.Z., Wang H.T., Lin Z.X., Zhang X.L., Fang D.D., and Zhang J.F., 2015b, A comparative Meta-analysis of QTL between intraspecific Gossypium hirsutum and interspecific G. hirsutum x G. barbadense populations, Mol. Genet. Genomics, 290(3): 1003-1025 https://doi.org/10.1007/s00438-014-0963-9 PMid:25501533

Shen X.L., Guo W.Z., Lu Q.X., Zhu X.F., Yuan Y.L., and Zhang T.Z., 2007, Genetic mapping of quantitative trait loci for fiber quality and yield trait by RIL approach in upland cotton, Euphytica, 155(3): 371-380 https://doi.org/10.1007/s10681-006-9338-6

Shi Y., Liu A., Li J., Zhang J., Li S., Zhang J., Ma L., He R., Song W., Guo L., Lu Q., Xiang X., Gong W., Gong J., Ge Q., Shang H., Deng X., Pan J., and Yuan Y., 2020, Examining two sets of introgression lines across multiple environments reveals background-independent and stably expressed quantitative trait loci of fiber quality in cotton, Theor. Appl. Genet., https://doi.org/10.1007/s00122-020-03578 -0 https://doi.org/10.1007/s00122-020-03578-0 PMid:32185421 PMCid:PMC7311500 
Stuber C.W., Lincoln S.E., Wolff D.W., Helentjaris T., and Lander E.S., 1992, Identification of genetic factors contributing to heterosis in a hybrid from two elite maize inbred lines using molecular markers, Genetics, 132(3): 823-839

Tan Z.Y., 2018, QTL mapping for fiber quality traits and fine mapping and candidate gene identification of qFS15 in upland cotton, Dissertation for Ph.D., Chongqing: Southwest University, Supervisor: Zhang Z.S., pp.15-16

Tang L.Y., Li X.X., Zhang S.J., Wang H.T., Liu C.J., Zhang X.Y., and Zhang J.H., 2018, QTL Mapping for photosynthesis related traits in upland cotton, Zuowu Zazhi (Crops), (5): 85-90

Tang S.Y., Teng Z.H., Zhai T.F., Fang X.M., Liu F., Liu D.J., Zhang J., Liu D.X., Wang S.F., Zhang K., Shao Q.S., Tan Z.Y., Paterson A.H., and Zhang Z.S., 2015, Construction of genetic map and QTL analysis of fiber quality traits for upland cotton (Gossypium hirsutum L.), Euphytica, 201: 195-213 https://doi.org/10.1007/s10681-014-1189-y

Wang J.K., Wan X.Y., Li H.H., Pfeiffer W.H., Crouch J., and Wan J.M., 2007, Application of identified QTL marker associations in rice quality improvement through a design-breeding approach, Theor. Appl. Genet., 115: 87-100 https://doi.org/10.1007/s00122-007-0545-X PMid:17479243

Xu P., Gao J., Cao Z., Chee P.W., Guo Q., Xu Z.Z., Paterson A.H., Zhang X.G., and Shen X.L., 2017, Fine mapping and candidate gene analysis of $q$ FL-chr1, a fiber length QTL in cotton, Theor. Appl. Genet., 130: 1309-1319 https://doi.org/10.1007/s00122-017-2890-8 PMid:28361363

Yang X.L., Zhou X.D., Wang X.F., Li Z.K., Zhang Y., Liu H.W., Wu L. Q., Zhang G.Y., Yan G.J., and Ma Z.Y., 2015, Mapping QTL for cotton fiber quality traits using simple sequence repeat markers, conserved intron-scanning primers, and transcript derived fragments, Euphytica, 201: 215-230 https://doi.org/10.1007/s10681-014-1194-1

Yu J., Jung S., Cheng C.H., Ficklin S.P., Lee T., Zheng P., Jones D., Percy R.G., and Main D., 2014a, CottonGen: a genomics, genetics and breeding database for cotton research, Nucleic Acids Res., 42: D1229-D1236

https://doi.org/10.1093/nar/gkt1064 PMid:24203703 PMCid:PMC3964939

Yu J.Z., Ulloa M., and Hoffman S.M., 2014b, Mapping genomic loci for cotton plant architecture, yield components, and fiber properties in an interspecific (Gossypium hirsutum L. x G. barbadense L.) RIL population, Mol. Genet. Genomics, 289(6): 1347 https://doi.org/10.1007/s00438-014-0930-5 PMid:25314923

Yu Y., Yuan D., Liang S., Li X.M., Wang X.Q., Lin Z.X., and Zhang X.L., 2011, Genome structure of cotton revealed by a genome-wide SSR genetic map constructed from a $\mathrm{BC}_{1}$ population between Gossypium hirsutum and G. barbadense, BMC Genomics, 12(1): 15 https://doi.org/10.1186/1471-2164-12-15 PMid:21214949 PMCid:PMC3031231

Zhang J., Wu Y.T., Guo W.Z., and Zhang T.Z., 2000, Fast screening of microsatellite markers in cotton with PAGE/silver staining, Mianhua Xuebao (Acta Gossypii Sinica), 12(5): 267-269

Zhang Y., Wang X.F., Li Z.K., Zhang G.Y., and Ma Z.Y., 2011, Assessing genetic diversity of cotton cultivars using genomic and newly developed expressed sequence tag derived microsatellite markers, Genet. Mol. Res., 10: 1462-1470 https://doi.org/10.4238/vol10-3gmr1277 PMid:21823096

Zhang Z, Li J, Muhammad J, Cai J., Jia F., Shi Y.Z., Gong J.W., Shang H.H., Liu A.Y., Chen T.T., Ge Q., Palanga K.K., Lu Q.W., Deng X.Y., Tan Y.N., Li W., Sun L.Y., Gong W.K., and Yuan Y.L., 2015, High-resolution consensus mapping of quantitative trait loci for fiber strength, length and micronaire on chromosome 25 of the upland cotton (Gossypium hirsutum L.), PLoS One, 10(8): e0135430 https://doi.org/10.1371/journal.pone.0135430 PMid:26262992 PMCid:PMC4532425

Zhang Z., 2015, Construction of SNP genetic map and identification of QTLs for yield and fiber quality traits in upland cotton (Gossypium hirsutum), Thesis for M.S., Chinese Academy of Agricultural Sciences, Supervisor: Yuan Y.L., pp.1-2

Zhang Z.S., Xiao Y.H., Luo M., Li X.B., Luo X.Y., Hou L., Li D.M., and Pei Y., 2005, Construction of a genetic linkage map and QTL analysis of fiber-related traits in upland cotton (Gossypium hirsutum L.), Euphytica, 144: 91-99 https://doi.org/10.1007/s10681-005-4629-x 